\title{
BMJ Open Cohort profile: Alliance for Quality Assessment in Healthcare-Dialysis (AQuAH-D) prospective cohort study of patients on haemodialysis in Japan
}

\author{
Sayaka Shimizu (D) , ${ }^{1,2}$ Yoshihiro Onishi, ${ }^{1}$ Koji Kabaya, ${ }^{1}$ Jui Wang, ${ }^{1,3}$ \\ Shingo Fukuma (D) , ${ }^{4}$ Jun Morinaga, ${ }^{5}$ Shingo Hatakeyama (D) , ${ }^{6}$ Shinya Kobayashi, ${ }^{7}$ \\ Kazuyuki Maeno, ${ }^{8}$ Hajime Yamazaki, ${ }^{2}$ Shunichi Fukuhara ${ }^{2,9,10}$
}

To cite: Shimizu S, Onishi Y, Kabaya K, et al. Cohort profile: Alliance for Quality Assessment in HealthcareDialysis (AQuAH-D) prospective cohort study of patients on haemodialysis in Japan. BMJ Open 2022;12:e054427. doi:10.1136/ bmjopen-2021-054427

- Prepublication history and additional supplemental material for this paper are available online. To view these files, please visit the journal online (http://dx.doi.org/10.1136/ bmjopen-2021-054427)

Received 15 June 2021 Accepted 09 December 2021

Check for updates

(C) Author(s) (or their employer(s)) 2022. Re-use permitted under CC BY-NC. No commercial re-use. See rights and permissions. Published by BMJ.

For numbered affiliations see end of article.

Correspondence to Dr Sayaka Shimizu; shimizu@i-hope.jp

\section{ABSTRACT}

Purpose The global burden of kidney failure is increasing, but the treatment of kidney failure varies widely between patients, between dialysis facilities and over time. The Alliance for Quality Assessment in Healthcare-Dialysis (AQuAH-D) aims to conduct efficient and timely cohort studies on associations between those variations and clinical and patient-reported outcomes.

Participants Included are outpatients aged 20 years old or older who are undergoing haemodialysis and have consented to participate. A total of 2895 patients were enrolled from 25 facilities in Japan between August 2018 and July 2020 and are to be followed until 31 December 2026. Chart review and annual questionnaires are used to collect data on patient characteristics and on outcomes including quality of life. Data on medications, haemodialysis prescriptions and blood tests are obtained from existing electronic records. Data are collected retrospectively from 1 January 2017 to patient enrolment, and prospectively from patient enrolment until the end of December 2026.

Findings to date To date, the mean age is 68.3 (SD 12.2) years and $35.2 \%$ are female. The most common cause of kidney failure is diabetic nephropathy (37.4\%). In January 2020 , the facilities' median weekly doses of erythropoietin stimulating agent (ESA) and of intravenous vitamin D ranged from 1846 to $9692 \mathrm{IU}$ (epoetin alfa equivalent) and 0.78 to $2.25 \mu \mathrm{g}$ (calcitriol equivalent), respectively. The facilities' percentages of patients to whom calcimimetics are prescribed varied from $19 \%$ to $79 \%$. During the retrospective period (averaging 1.85 years per participant), the incidence rates of any hospitalisation and of hospitalisation due to cardiovascular disease were 67.2 and 12.0 per 100 person-years, respectively.

Future plans AQUAH-D data will be updated every 6 months and will be available for studies addressing a wide range of research questions, using the advantages of granular data and quality-of-life measurement of ageing patients on haemodialysis.

\section{INTRODUCTION}

Kidney failure is an important noncommunicable disease. The number of people receiving kidney replacement

\section{Strengths and limitations of this study}

- The Alliance for Quality Assessment in HealthcareDialysis, a multicentre prospective cohort of outpatients on haemodialysis in Japan. It will be updated every 6 months and will provide valuable data that can be used for timely studies on changing haemodialysis practice.

- With electronic records of highly granular, sequential practice-related data and data on outcomes including quality of life, a wide range of important research questions are expected to be addressed.

- Results from this cohort study are expected to inform approaches to the problems of ageing and multimorbidity of patients on haemodialysis, which are becoming more important worldwide.

- We are not attempting to construct a representative sample of dialysis facilities in Japan.

- We are unable to include data on prescriptions or examinations from facilities other than those participating in the study.

therapy (KRT, either dialysis or kidney transplantation) worldwide was estimated to be 2.6million in 2010 and is expected to reach 5.4 million by $2030 .{ }^{1}$ Kidney transplantation is preferred because of its favourable effects on prognosis and on quality of life (QOL). ${ }^{2}$ However, haemodialysis is currently the mainstay of KRT especially in eastern and southeastern Asia including Japan, where deceased-donor organ transplantation is relatively rare, probably due to cultural context. ${ }^{34}$ In Japan, approximately 300000 people were on maintenance haemodialysis in 2018 and the number is increasing. ${ }^{5}$

Variations in haemodialysis practice have been described in observational studies, and possible associations of patient outcomes with patient-level, institutional and temporal variations have been evaluated..$^{6-8}$ Management of kidney failure with haemodialysis requires 
attention to anaemia, ${ }^{9}$ mineral-bone disorder (MBD), ${ }^{10}$ dialysis prescriptions, ${ }^{11}$ vascular access, ${ }^{12}$ comorbidities (diabetes mellitus, cardiovascular disease, ${ }^{13} 14$ etc) and changes over time. A database allowing questions about management of kidney failure to be answered quickly and efficiently would be useful. Researchers lack information that is granular enough to facilitate investigation of those questions.

Because Japan's population is ageing faster than those in many other parts of the world, it is already dealing with the problems of ageing and multimorbidity of patients on haemodialysis that are starting to emerge in some other countries. ${ }^{15}$ In addition to survival, ${ }^{16}$ patient-reported outcomes (PROs), including QOL and symptoms, are important outcomes in this chronically ill and ageing population. In that context, we see an unmet need for a haemodialysis cohort database that includes both PROs and highly granular data, and for that database to be updated frequently and to be quickly available to researchers.

The Alliance for Quality Assessment in HealthcareDialysis (AQuAH-D), was established (1) to describe patient-level and facility-level variations in dialysis practice, (2) to investigate the factors explaining and predicting variations in dialysis practice and (3) to investigate associations between variations in dialysis practice and clinical outcomes including PROs among ageing patients on maintenance haemodialysis in Japan. To achieve those objectives, we have established a system to frequently collect highly granular data, and to share them with researchers without delay.

\section{COHORT DESCRIPTION}

\section{Study design and Setting}

This is a multicentre prospective cohort study of clinics and hospitals with outpatient haemodialysis centres in Japan. Facility recruitment started in September 2018 and participants are recruited from the time of facility participation until 30 June 2026. Follow-up is intended to continue until the end of December 2026.

\section{Participants}

Outpatients aged 20 years old or older, the age at which people in Japan are legally considered to be adults, who are undergoing maintenance haemodialysis and have consented to participate are being included. Patients who receive peritoneal dialysis are being excluded, because we have not established a sustainable method to collect sufficient data on peritoneal dialysis, due to the lack of facility-by-facility electronic data on variables relevant to research, such as daily dialysis prescriptions over time. This cohort is open: Patients who were attending a facility at the time of the start of that facility's participation and those who begin coming to the facility thereafter until 30 June 2026 are candidates for enrolment.

\section{Data sources and data collection}

In principle, the data come from three types of sources: existing electronic records of practice-related data, chart

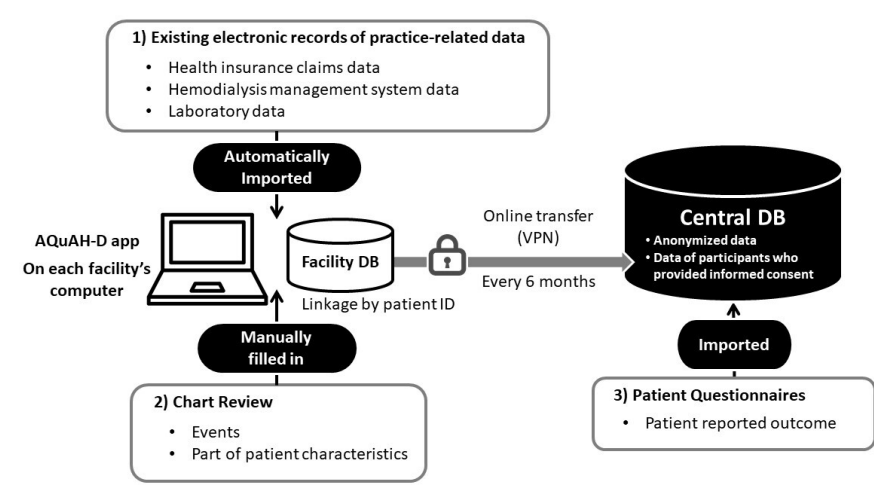

Figure 1 Data sources and data collection via the custommade application software AQuAH-D app. Health insurance claims data are generated for reimbursement at each facility. Haemodialysis management systems are used by healthcare providers to manage haemodialysis prescriptions, to record the results of haemodialysis sessions, to hold data on patient characteristics and to hold data from each dialysis session. AQuAH-D, Alliance for Quality Assessment in HealthcareDialysis; DB, database, VPN, virtual private network.

review and patient-completed questionnaires (figure 1). A unique application software called AQuAH-D app, installed on each facility's computer, is used to integrate the data by patient ID, to create the facility database and to transfer the participants' anonymised data to the central database every 6 months.

Data source 1: existing electronic records of practice-related data To minimise the burden of data collection, we use each facility's existing electronic records of practice-related data: health insurance claims data, haemodialysis management system data and laboratory data. Health insurance claims data are generated for reimbursement at each facility every month. Haemodialysis management systems are used by healthcare providers to manage haemodialysis prescriptions and to record the results of haemodialysis sessions. The systems hold data on patient characteristics and data from each dialysis session. Haemodialysis management systems marketed by NIPRO (Osaka, Japan), Nikkiso (Tokyo, Japan), TORAY (Tokyo, Japan), Green Information Systems (Okayama, Japan), MySystem (Okayama, Japan), MEDIBRAINS (Fukuoka, Japan) and SYSTEM RESEARCH (Hyogo, Japan) were either already able to create data files that can be imported into the AQuAH-D app, or such a function was added to them for this cohort. In principal, these existing electronic records of practice-related data are imported into the AQuAH-D app by medical staff once each month.

\section{Data source 2: chart review}

Event data and data on patient characteristics that are not in the existing electronic records are obtained by reviewing medical charts. The AQuAH-D app displays a data-entry form to the user, based on the data imported automatically into the facility database. The form is manually filled in by trained facility staff or clinical research coordinators. 


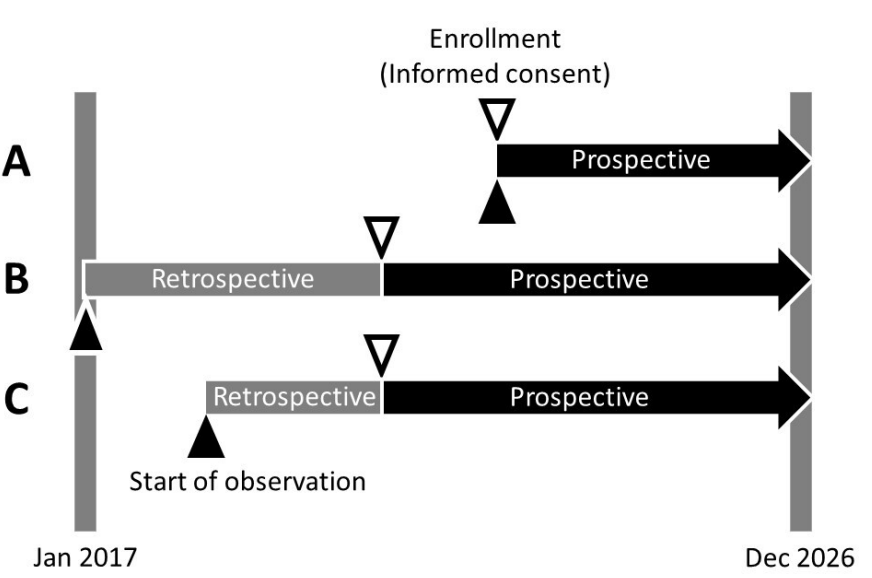

Figure 2 Observation period: retrospective period and prospective period. The start of observation $(\mathbf{\Delta})$ is defined for each participant as 1 January 2017 or the patient's first day of haemodialysis in the facility, whichever is later. The retrospective period is from the start of observation to patient enrolment ( $\nabla$, time of informed consent), and the prospective period is from patient enrolment to 31 December 2026. Case (A) participants who start haemodialysis on or after 1 January 2017 and provide informed consent when they start haemodialysis at the facility. No retrospective period. Case (B) participants who were already visiting the facility as haemodialysis patients on 1 January 2017. Retrospective period: 1 January 2017 to patient enrolment. Case (C) participants whose first visit to the facility as a haemodialysis patient was on or after 1 January 2017. Retrospective period: from the patient's first day of haemodialysis in the participating facility to the date of patient enrolment. In all cases, the prospective period is from patient enrolment through 31 December 2026.

\section{Data source 3: patient questionnaires}

Patient questionnaires, including those used to measure PROs, are distributed on paper once a year. The responses are converted into electronic form at the Institute for Health Outcomes and Process Evaluation Research (iHope International). The resulting electronic records are also imported to the central database and linked to other data.

\section{Observation period}

In principle, data acquisition starts at the time of patient enrolment and continues until the end of study, which will be the end of December 2026 (the prospective period, figure 2A). However, if a participant underwent outpatient haemodialysis at the same facility from January 2017 to enrolment, then data from existing electronic records, as well as data from chart review, were also obtained (the retrospective period, figure 2B,C). A participant's first day or 1 January 2017 of haemodialysis in the facility, whichever is later, is defined as the start of observation. The observation ends with death, kidney transplantation, withdrawal of consent, transfer to another facility, discontinuation of dialysis or transfer either to home dialysis or to peritoneal dialysis.

\section{Variables}

The measured variables, data sources and timing of measurements are summarised in table 1. Data on the patients' characteristics are collected primarily from existing electronic records, and are supplemented by chart review or patient questionnaires. Practice-related data and data on haemodialysis results from existing electronic records are recorded at the time of each dialysis visit, that is, about 13 days per month. Laboratory data measured as part of usual practice are recorded approximately one to four times a month.

Outcome data consist of PROs and events. PROs are measured at the time of patient enrolment and annually thereafter, and event data are collected when a predefined event occurs. Data on 7 kinds of events are collected: death, hospitalisation, kidney transplantation, vascularaccess intervention, transfer to another facility, discontinuation of dialysis and transfer to peritoneal dialysis or to home dialysis. The plan is to measure QOL repeatedly by using the Quality of Life General-10, ${ }^{17}$ the QOL Disease Impact Scale, ${ }^{18}$ and the Kidney Disease Quality of Life instrument. ${ }^{19}$ Details of other PROs to be measured will be revised. Table 1 shows the content of the first questionnaire, which is used at the time of facility enrolment.

\section{Data availability}

Data collected in the central database are converted into patient-level data with a format suitable for analysis. Participating facilities receive datasets generated from their own facility data, and are free to use them. All data from the AQuAH-D cohort are also available for use by participating institutions or third-party organisations under the following conditions: Each research question must be submitted to the publication steering committee, the committee must judge it to be relevant, and the committee must approve the validity of the study design.

\section{Patient and public involvement}

Patients and the public were not engaged in the design, conduct, or reporting of this study.

\section{FINDINGS TO DATE}

\section{Facility and participant characteristics}

From 1 September 2018 to 31 July 2020, 2895 participants from 25 facilities in Japan were enrolled in the study. Of those 25 facilities, 19 were clinics and 6 were hospitals (clinics are defined as having 19 or fewer inpatient beds, and hospitals are defined as having 20 or more inpatient beds). The patient volume, that is, number of visiting outpatients on haemodialysis at the time of facility enrolment, was less than 100 in five facilities, 100-149 in 12 facilities, 150-199 in six facilities and 200 or more in two facilities. The facilities are located in 11 prefectures, from Hokkaido in the north to Kyushu in the south. Facility recruitment is continuing, and by 7 March 2021 more facilities had begun participating in this cohort. 
Table 1 Measured variables, data sources, and the timing of measurements

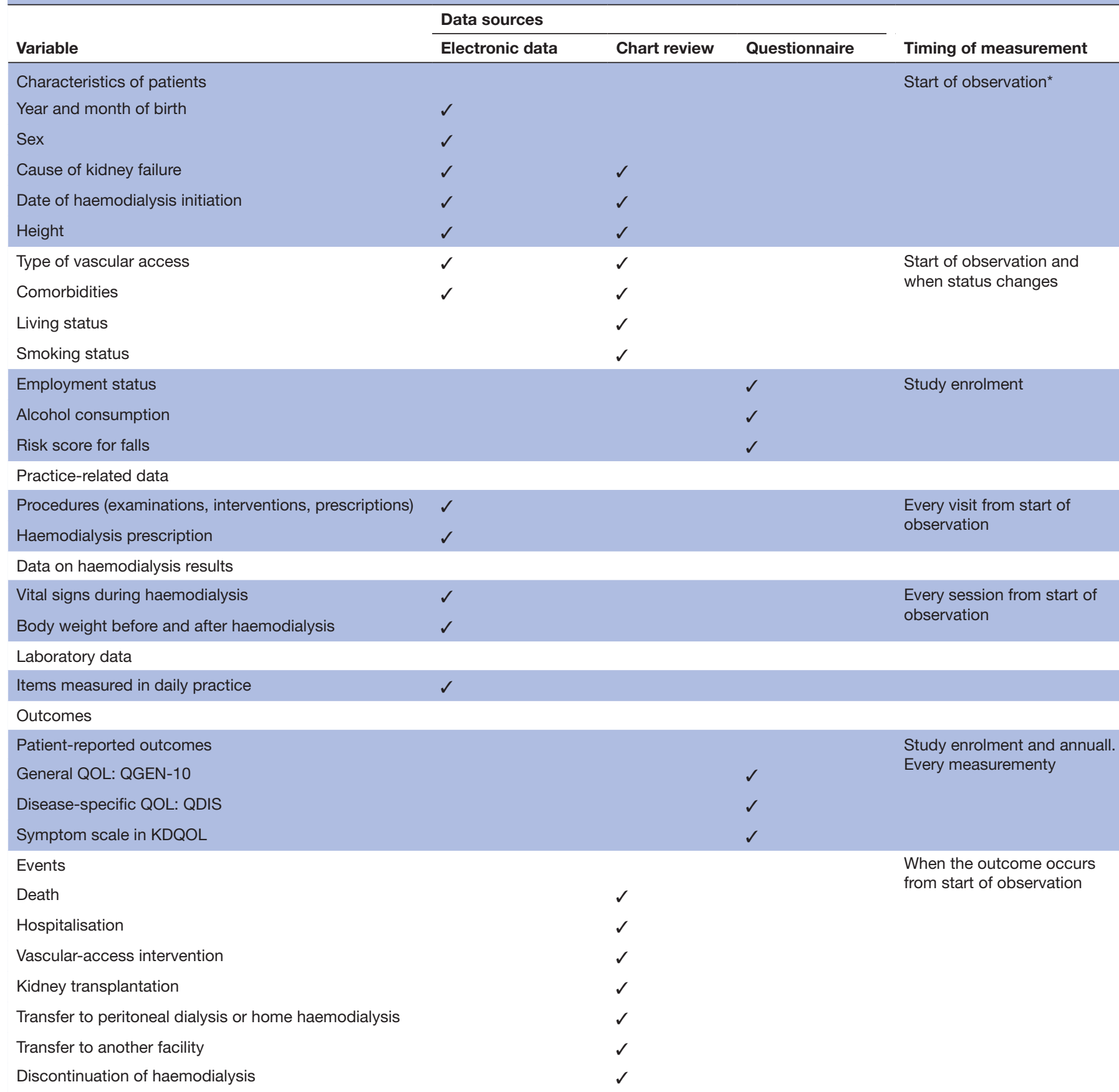

Risk score for falls. ${ }^{31}$

*Start of observation is defined for each participant as 1 January 2017 or the participant's first day of haemodialysis, whichever is later (figure 2). KDQOL, Kidney Disease Quality of Life instrument; QDIS, QOL Disease Impact Scale; QGEN-10, Quality of Life General-10; QOL, quality of life.

Participants' characteristics at the time of enrolment (figure 2) are shown in table 2 together with demographic information from the Japanese Society of Dialysis Therapy (JSDT) Registry in 2018. That registry includes survey results from $94.7 \%$ of all dialysis facilities, and thus, it covers nearly all patients on dialysis in Japan..$^{5}$ In the AQuAH-D cohort, the mean age was 68.3 (SD 12.2) years and $35.2 \%$ were female. The most frequent cause of kidney failure was diabetic nephropathy (37.4\%), followed by glomerulonephritis $(28.4 \%)$. These results were similar to those in the JSDT Registry.

\section{Data from existing electronic records}

As examples of existing electronic records of practicerelated data, figure 3 shows the administration status of ESA for renal anaemia, intravenous vitamin D and calcimimetics for MBD management at each facility in January 2020, where data for the month is currently available. 
Table 2 Baseline characteristics of participants in the AQuAH-D cohort and of Japan's dialysis population

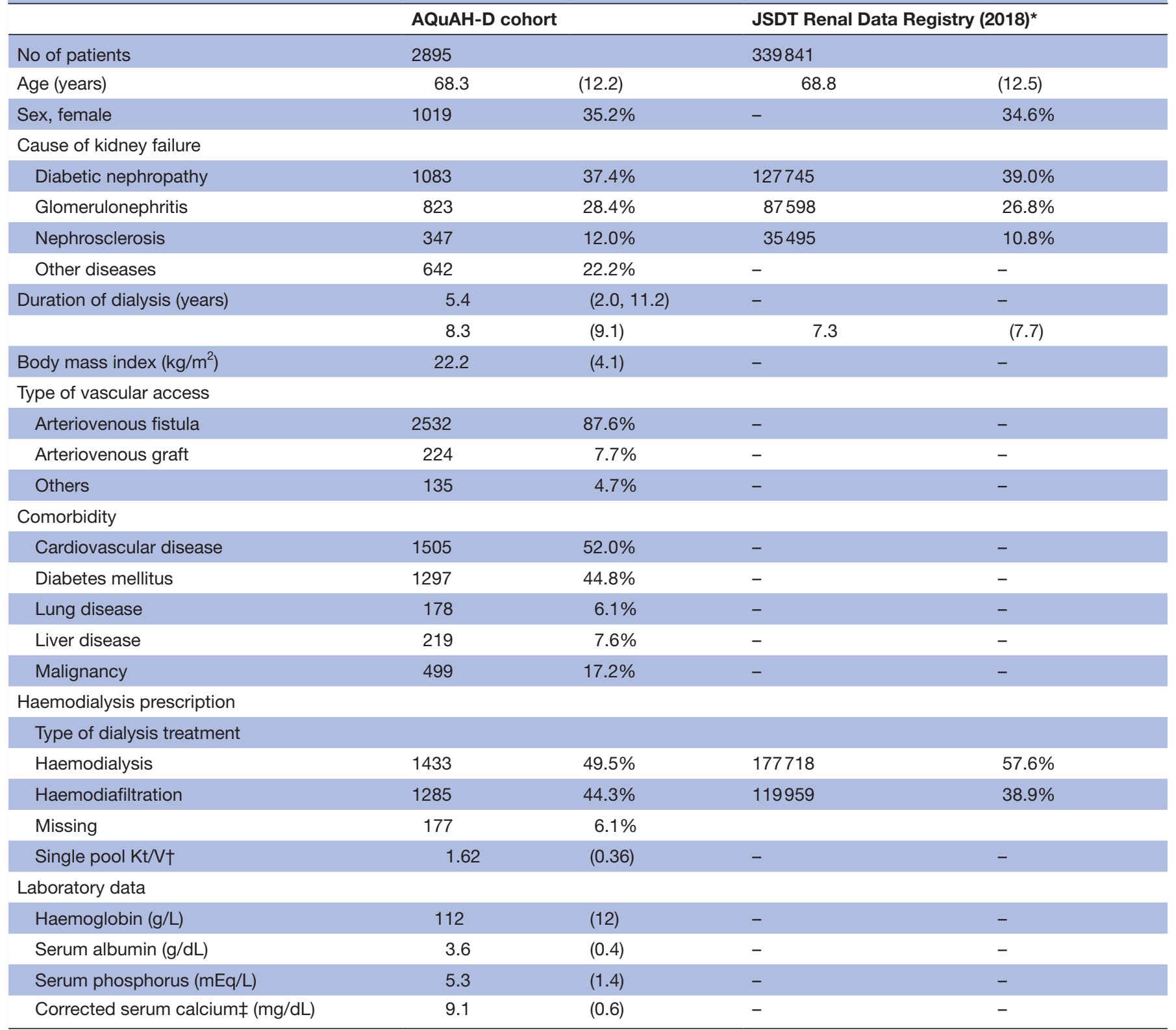

Continuous variables are described by the mean (SD) or the median (IQR), and categorical variables are described by the number and percentage. ${ }^{*}$ Results of a survey carried out by the Japanese Society for Dialysis Therapy, in December $2018 .{ }^{5}$ The JSDT registry includes about 9000 patients on peritoneal dialysis. Percentages were calculated among participants without missing data.

$\dagger$ Single pool Kt/ $\mathrm{V}$ values were calculated using the equation by Daugirdas. ${ }^{32}$

$\ddagger$ Serum calcium values were corrected for albumin concentration using a modified version of Payne's formula. ${ }^{33}$

AQuAH-D, Alliance for Quality Assessment in Healthcare-Dialysis; JSDT, Japanese Society for Dialysis Therapy.

The median doses of ESA and of intravenous vitamin D ranged from 1846 to 9692 IU per week and from 0.78 to $2.25 \mu \mathrm{g}$ per week, respectively. The percentage of patients to whom calcimimetics were prescribed varied by facility, from $19 \%$ to $79 \%$.

\section{Incidence of hospitalisations and vascular-access} interventions in the retrospective period

During the retrospective periods, the total observation time was 5356 person-years (an average of 1.85 years). The incidence rate of any hospitalisation was 67.2 per 100 person-years, and the most common cause of hospitalisation was vascular-access complication, followed by cardiovascular disease (19.8 and 12.0 per 100 personyears, respectively). The incidence rate of vascular-access intervention, which can be done as an outpatient treatment, was 60.6 per 100 person-years. Details are shown in online supplemental table 1.

\section{STRENGTHS AND LIMITATIONS}

The AQuAH-D is a multicentre cohort of outpatients on haemodialysis in Japan. With electronic records of practice-related data and data on outcomes including 
A

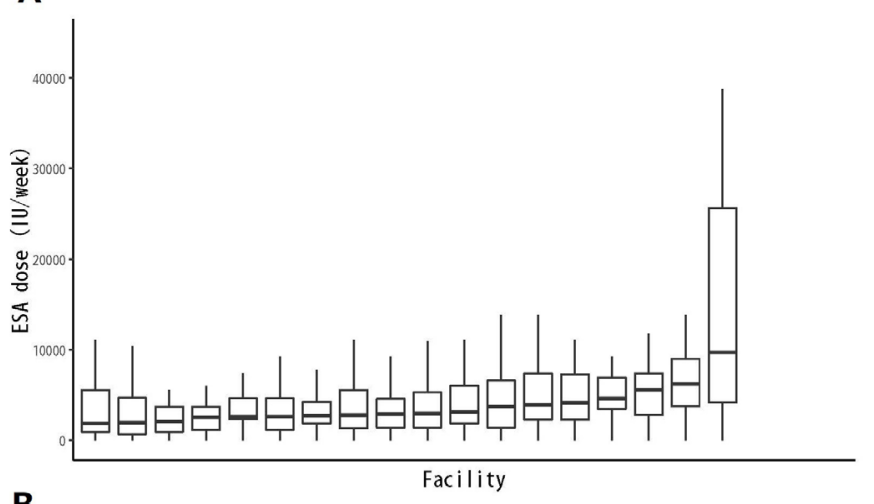

B

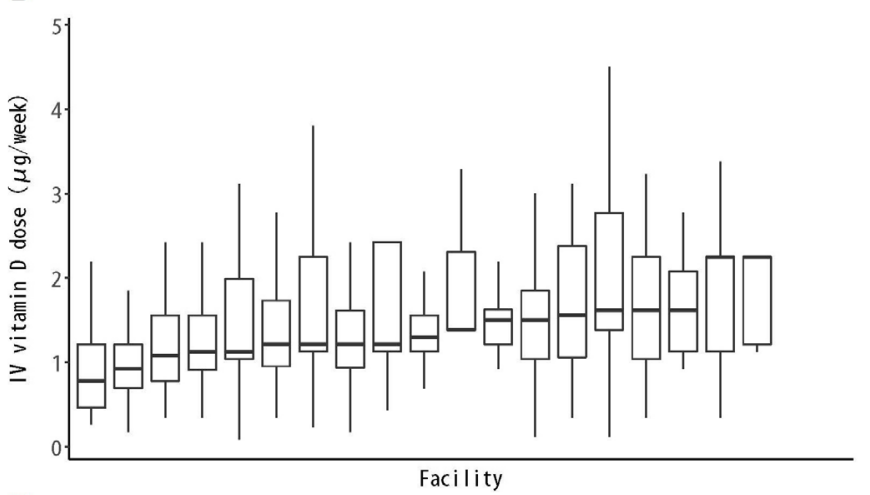

C

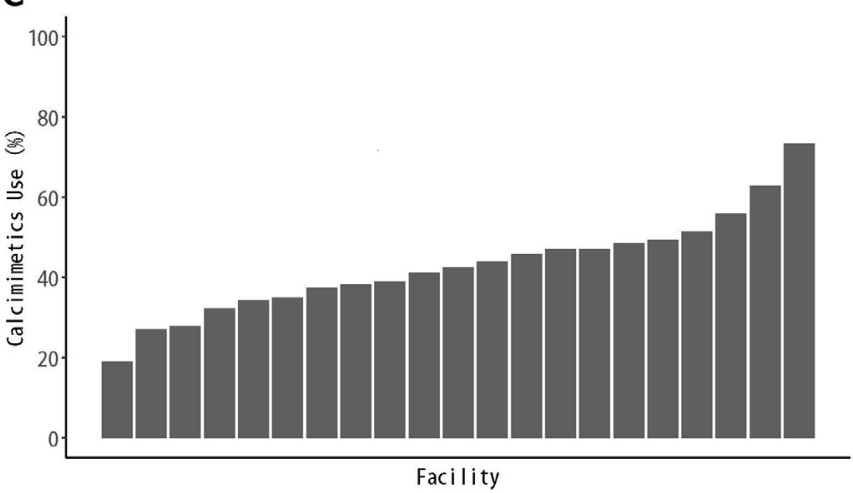

Figure 3 Prescription status of the three medications in each facility in January 2020. Boxplots indicate medians and IQRs of the doses of erythropoietin stimulating agent (ESA) (A), and of intravenous vitamin $D(B)$. The percentages of patients who received calcimimetics (C) are shown in the bar chart. The doses of ESA and of intravenous vitamin D were converted into erythropoietin alfa dose (erythropoietin alfa:darbepoietin alfa:epoetin beta pegol $=1: 200^{34}: 225^{35}$ and calcitriol dose (maxacalcitoriol:calcitriol $=1: 7,{ }^{36}$ respectively).

QOL, a wide range of important research questions are expected to be addressed.

To clarify the strengths and limitations of this cohort, online supplemental table 2 shows a summary of some major characteristics of the AQuAH-D together with those of four other registries: the US Renal Data System database,${ }^{20-22}$ the European Renal Association-European Dialysis and Transplant Association Registry, ${ }^{23-25}$ the JSDT Renal Data Registry ${ }^{526}$ and the Dialysis Outcomes and Practice Patterns Study. ${ }^{27-29}$

\section{Strengths}

This study has several strengths. First, our unique software (the AQuAH-D app) enables us to automatically import patient data and thus minimise the administrative burden on facility staff. This advantage will contribute to cohort sustainability. In addition, the availability of highly granular, sequential, patient-level data is expected to allow researchers to address a wide range of research questions, including questions about the impact of various exposures on patient outcomes. The AQuAH-D-app can import data in a variety of formats. If each facility enters more of its data into electronic health records, then we will be able to collect data on more variables. Second, data from medical chart reviews are incorporated to address two common limitations of existing databases: missing data and misclassification..$^{22}{ }^{25}{ }^{30}$ For example, one major limitation of some existing large databases is a lack of accurate data on comorbidities, but in this cohort those data are collected (by chart review) (online supplemental table 2). Third, measuring QOL provides important information about patients with kidney failure ${ }^{16}$ and the plan here is to measure QOL repeatedly. Fourth, this cohort will provide information about problems that are emerging worldwide as a result of ageing and multimorbidity of patients on haemodialysis. Fifth, we consider the participating facilities to constitute a research consortium, and we encourage healthcare professionals there to use these data. We believe that will motivate participating facilities, which will help to sustain the cohort and will facilitate research on clinically relevant questions.

\section{Limitations}

There are several limitations. First, we are not attempting to construct a representative sample of dialysis facilities in Japan. In addition, only those participants who give their informed consent are included, which might result in the participants being healthier or younger than Japan's haemodialysis population as a whole. Especially in descriptive studies, researchers should recognise that generalisability of the results is limited. Second, we are unable to include data on prescriptions or examinations from facilities other than those participating in the study. Third, data pertaining to the retrospective period (1 January 2017 to the time of patient enrolment) come from participants who survive until the time of enrolment, so inferences from those data can be affected by selection bias.

\section{Author affiliations}

${ }^{1}$ Department of Research, Institute for Health Outcomes \& Process Evaluation Research, Kyoto, Japan

${ }^{2}$ Section of Clinical Epidemiology, Department of Community Medicine, Graduate School of Medicine, Kyoto University, Kyoto, Japan

${ }^{3}$ Institute of Epidemiology and Preventive Medicine, College of Public Health, National Taiwan University, Taipei, Taiwan

${ }^{4}$ Department of Human Health Sciences, Graduate School of Medicine, Kyoto University, Kyoto, Japan

${ }^{5}$ Department of Nephrology, Graduate School of Medical Sciences, Kumamoto University, Kumamoto, Japan

${ }^{6}$ Department of Urology, Hirosaki University School of Medicine Graduate School of Medicine, Hirosaki, Japan

${ }^{7}$ Miyanosawa Nephro-Urology Clinic, Hokkaido, Japan 
${ }^{8}$ Jinyukai Hospital, Hokkaido, Japan

${ }^{9}$ Department of Health Policy and Management, Johns Hopkins University

Bloomberg School of Public Health, Baltimore, Maryland, USA

${ }^{10}$ Department of General Medicine, Shirakawa Satellite for Teaching and Research (STAR), Fukushima Medical University, Fukushima, Japan

\section{Twitter Shingo Hatakeyama @ShingoHatakeya1}

Acknowledgements We gratefully acknowledge the following facilities for their participation: Jinyukai Hospital, Kotoni nephrology and urology clinic; Miyanosawa nephrourology clinic; Sumijin Clinic; Toyota Urology Clinic; Oyokyo Kidney Research Institute, Hirosaki Hospital; Shibagaki Dialysis Clinic Jiyugaoka; Shibagaki Dialysis Clinic Kugahara; Shibagaki Dialysis Clinic Togoshi; Nagoya Memorial Foundation, Kanayama Clinic; Chibune Clinic; Chibune General Hospital; Fujiidera Keijinkai Clinic; Hakuyu Chiyoda Clinic; Nishizaki Internal Medicine Clinic; Tsuyama Chuo Kinen Hospital; Kamikawa Clinic; Kaifu Clinic; Kinashi Obayashi Hospital; lizuka Hospital; Matsuyama Clinic Oita Nephro Internal Medicine Department; Department of Nephrology, Akebono Clinic; Akebono Daini Clinic; Jinseikai Clinic Hikarinomori; Jinseikai Clinic Kurokami; Jinseikai Clinic Nagamine; Jinseikai Clinic Oodu; Uki Clinic; Jinseikai Clinic Shinyashiki; Kumamoto Urological Hospital; Shimada Hospital; and Yayamachi Fukushima Clinic.

Contributors SS took responsibility for the work and the conduct of the study, had access to the data, controlled the decision to publish, the integrity of the data, and the accuracy of the data analysis. Concept and design: ShiF and ShuF. Acquisition, analysis or interpretation of data: SS, YO, KK, JW and ShuF. Drafting of the manuscript: SS, YO and KK. Critical revision of the manuscript for important intellectual content: all authors. All authors meet the full authorship criteria.

Funding The authors have not declared a specific grant for this research from any funding agency in the public, commercial or not-for-profit sectors.

Competing interests None declared.

Patient consent for publication Not applicable.

Ethics approval This study was approved by the Ethical Review Committee of iHope International (Approval number: 2017A0102). It is being conducted in accordance with the Declaration of Helsinki and with Japan's ethical guidelines for medical and health research involving human subjects (https://www.mhlw.go.jp/ content/10600000/000757206.pdf).

Provenance and peer review Not commissioned; externally peer reviewed.

Data availability statement Data are available on reasonable request and when approved by the publication steering committee. Researchers who are interested in collaboration can contact us by email (aqd@i-hope.jp). Data are available on reasonable request and when approved by the publication steering committee. Researchers who are interested in collaboration can contact us by email (aqd@ i-hope.jp)

Supplemental material This content has been supplied by the author(s). It has not been vetted by BMJ Publishing Group Limited (BMJ) and may not have been peer-reviewed. Any opinions or recommendations discussed are solely those of the author(s) and are not endorsed by BMJ. BMJ disclaims all liability and responsibility arising from any reliance placed on the content. Where the content includes any translated material, BMJ does not warrant the accuracy and reliability of the translations (including but not limited to local regulations, clinical guidelines, terminology, drug names and drug dosages), and is not responsible for any error and/or omissions arising from translation and adaptation or otherwise.

Open access This is an open access article distributed in accordance with the Creative Commons Attribution Non Commercial (CC BY-NC 4.0) license, which permits others to distribute, remix, adapt, build upon this work non-commercially, and license their derivative works on different terms, provided the original work is properly cited, appropriate credit is given, any changes made indicated, and the use is non-commercial. See: http://creativecommons.org/licenses/by-nc/4.0/.

\section{ORCID iDs}

Sayaka Shimizu http://orcid.org/0000-0001-9283-144X

Shingo Fukuma http://orcid.org/0000-0002-8379-8761

Shingo Hatakeyama http://orcid.org/0000-0002-0026-4079
REFERENCES

1 Liyanage T, Ninomiya T, Jha V, et al. Worldwide access to treatment for end-stage kidney disease: a systematic review. Lancet 2015;385:1975-82.

2 Tonelli M, Wiebe N, Knoll G, et al. Systematic review: kidney transplantation compared with dialysis in clinically relevant outcomes. Am J Transplant 2011;11:2093-109.

3 Robinson BM, Akizawa T, Jager KJ, et al. Factors affecting outcomes in patients reaching end-stage kidney disease worldwide: differences in access to renal replacement therapy, modality use, and haemodialysis practices. Lancet 2016;388:294-306.

4 Akabayashi A, Nakazawa E, Ozeki-Hayashi R, et al. Twenty years after enactment of the organ transplant law in Japan: why are there still so few deceased donors? Transplant Proc 2018;50:1209-19.

5 Nitta K, Goto S, Masakane I, et al. Annual dialysis data report for 2018, JSDT renal data registry: survey methods, facility data, incidence, prevalence, and mortality. Renal Replacement Therapy 2020;6.

6 Robinson BM, Tong L, Zhang J, et al. Blood pressure levels and mortality risk among hemodialysis patients in the dialysis outcomes and practice patterns study. Kidney Int 2012;82:570-80.

7 Kawaguchi T, Karaboyas A, Robinson BM, et al. Associations of frequency and duration of patient-doctor contact in hemodialysis facilities with mortality. J Am Soc Nephrol 2013;24:1493-502.

8 Sood MM, Larkina M, Thumma JR, et al. Major bleeding events and risk stratification of antithrombotic agents in hemodialysis: results from the DOPPS. Kidney Int 2013;84:600-8.

9 Yamamoto H, Nishi S, Tomo T, et al. 2015 Japanese Society for dialysis therapy: guidelines for renal anemia in chronic kidney disease. Renal Replacement Therapy 2017;3.

10 Fukagawa M, Yokoyama K, Koiwa F, et al. Clinical practice guideline for the management of chronic kidney disease-mineral and bone disorder. Ther Apher Dial 2013;17:247-88.

11 Watanabe Y, Kawanishi H, Suzuki K, et al. Japanese society for dialysis therapy clinical guideline for "Maintenance hemodialysis: hemodialysis prescriptions". Ther Apher Dial 2015;19 Suppl 1:67-92.

12 Kukita K, Ohira S, Amano I, et al. 2011 update Japanese Society for dialysis therapy guidelines of vascular access construction and repair for chronic hemodialysis. Ther Apher Dial 2015;19 Suppl 1:1-39.

13 Nakao T, Inaba M, Abe M, et al. Best practice for diabetic patients on hemodialysis 2012. Ther Apher Dial 2015;19 Suppl 1:40-66.

14 Hirakata H, Nitta K, Inaba M, et al. Japanese Society for dialysis therapy guidelines for management of cardiovascular diseases in patients on chronic hemodialysis. Ther Apher Dial 2012;16:387-435.

15 Kimata N, Tsuchiya K, Akiba T, et al. Differences in the characteristics of dialysis patients in Japan compared with those in other countries. Blood Purif 2015;40:275-9.

16 Ishiwatari A, Yamamoto S, Fukuma S, et al. Changes in quality of life in older hemodialysis patients: a cohort study on dialysis outcomes and practice patterns. Am J Nephrol 2020;51:650-8.

17 Ware JE, Gandek B. Measuring physical and emotional health with quality of life General (QGEN囚) surveys: a user guide for single-item short forms. Second edition. Watertown, MA: John Ware Research Group, 2019.

18 Ware JE, Gandek B, Guyer R, et al. Standardizing disease-specific quality of life measures across multiple chronic conditions: development and initial evaluation of the QOL disease impact scale (QDIS®). Health Qual Life Outcomes 2016;14:84.

19 Green J, Fukuhara S, Shinzato T, et al. Translation, cultural adaptation, and initial reliability and multitrait testing of the kidney disease quality of life instrument for use in Japan. Qual Life Res 2001;10:93-100.

20 USRDS. About USRDS, 2021. Available: https://usrds.org/about/ [Accessed February 17, 2021].

21 Saran R, Robinson B, Abbott KC, et al. US renal data system 2019 annual data report: epidemiology of kidney disease in the United States. Am J Kidney Dis 2020;75:A6-7.

22 Foley RN, Collins AJ. The USRDS: what you need to know about what it can and can't tell us about ESRD. Clin J Am Soc Nephrol 2013;8:845-51.

23 European Renal Association-European Dialysis and Transplant Association. ERA-EDTA registry. Available: https://www.era-edta.org/ en/registry/ [Accessed February 17, 2021].

24 Kramer A, Boenink R, Noordzij M, et al. The ERA-EDTA registry annual report 2017: a summary. Clin Kidney J 2020;13:693-709.

25 Harambat J, Bonthuis M, Groothoff JW, et al. Lessons learned from the ESPN/ERA-EDTA registry. Pediatr Nephrol 2016;31:2055-64.

26 The Japanese Society for Dialysis Therapy. About JSDT. Available: https://www.jsdt.or.jp/english/ [Accessed February 17, 2021]. 
27 Arbor Research Collaborative for Health. Dialysis outcomes and practice patterns study. Available: https://www.dopps.org/ [Accessed February 17, 2021].

28 Pisoni RL, Gillespie BW, Dickinson DM, et al. The dialysis outcomes and practice patterns study (DOPPS): design, data elements, and methodology. Am J Kidney Dis 2004;44:7-15.

29 UMIN. UMIN clinical trials registry. Available: https://upload.umin.ac. jp/cgi-open-bin/icdr_e/ctr_view.cgi?recptno=R000041884 [Accessed Feburary 17, 2021].

30 Bikbov B, Purcell CA, Levey AS, et al. Global, regional, and national burden of chronic kidney disease, 1990-2017: a systematic analysis for the global burden of disease study 2017. Lancet 2020;395:709-33.

31 Okochi J, Toba K, Takahashi T, et al. Simple screening test for risk of falls in the elderly. Geriatrics and Gerontology International 2006;6:223-7.
32 Daugirdas JT. Second generation logarithmic estimates of singlepool variable volume Kt/V: an analysis of error. J Am Soc Nephrol 1993;4:1205-13.

33 Payne RB, Little AJ, Williams RB, et al. Interpretation of serum calcium in patients with abnormal serum proteins. Br Med J 1973;4:643-6.

34 Aljama P, Bommer J, Canaud B, et al. Practical guidelines for the use of NESP in treating renal anaemia. Nephrol Dial Transplant 2001;16:22-8.

35 Vega A, Abad S, Verdalles U, et al. Dose equivalence between continuous erythropoietin receptor activator (CERA), darbepoetin and epoetin in patients with advanced chronic kidney disease. Hippokratia 2014;18:315-8.

36 Ando R, Yoshikawa M, Yamashita Y, et al. Prospective comparison of the effects of maxacalcitol and of intravenous calcitriol on secondary hyperparathyroidism in chronic hemodialysis patients. Nihon Toseki Igakkai Zasshi 2003;36:317-25. 